\title{
Next generation chimeric antigen receptor T cells: safety strategies to overcome toxicity
}

\author{
Shengnan Yu, Ming Yi, Shuang Qin and Kongming Wu* (D)
}

\begin{abstract}
Chimeric antigen receptor T (CAR-T) cell therapy is an emerging and effective cancer immunotherapy. Especially in hematological malignancies, CAR-T cells have achieved exciting results. Two Anti-CD19 CAR-T therapies have been approved for the treatment of CD19-positive leukemia or lymphoma. However, the application of CAR-T cells is obviously hampered by the adverse effects, such as cytokines release syndrome and on-target off-tumor toxicity. In some clinical trials, patients quitted the treatment of CAR-T cells due to life-threatening toxicity. Seeking to alleviate these toxicities or prevent the occurrence, researchers have developed a number of safety strategies of CAR-T cells, including suicide genes, synthetic Notch receptor, on-switch CAR, combinatorial target-antigen recognition, bispecific T cell engager and inhibitory CAR. This review summarized the preclinical studies and clinical trials of the safety strategies of CAR-T cells and their respective strengths and weaknesses.
\end{abstract}

Keywords: Chimeric antigen receptor, Toxicity, Immunotherapy, Suicide gene, Synthetic notch receptor

\section{Introduction}

Many studies have proven that immunity plays an essential role in the development of cancers $[1,2]$. Therefore, immune therapies for malignant tumors including chimeric antigen receptor $\mathrm{T}$ (CAR-T) cells [3], bispecific antibodies [4], immune checkpoint inhibitors $[5,6]$, etc. have become research hotspots, and attracted the attention of more and more researchers and clinicians. In particular, as an adoptive cell therapy (ACT), CAR-based immunotherapy has achieved promising response $[7,8]$. Patient-derived $\mathrm{T}$ cells are modified to express a CAR that is mainly composed of extracellular single-chain variable fragment (scFv) recognizing tumor antigens, transmembrane domain, intracellular immunoreceptor tyrosinebased activation motifs (ITAMs) from CD3 zeta chain (CD3C) and co-stimulatory domain [9]. The CAR-T cells recognize tumor antigens and are activated independent of major histocompatibility complex (MHC) [10]. In order to enhance the activity and persistence

\footnotetext{
* Correspondence: kmwu@tjh.tjmu.edu.cn

Department of Oncology, Tongji Hospital of Tongji Medical College, Huazhong University of Science and Technology, 1095 Jiefang Avenue, Wuhan 430030, People's Republic of China
}

of CAR-T cells, researchers developed the second generation $\mathrm{CAR}$ containing one costimulatory domains (CD28 or $4-1 \mathrm{BB}$ or OX-40) and the third generation CAR containing two or more costimulatory domains on the basis of the first generation of CAR (no costimulatory domain) $[11,12]$. The fourth generation CAR-T cells, also called TRUCKs, are engineered to secrete transgenic cytokine like interleukin12 aiming at remodeling of tumor environment to promote therapeutic success $[13,14]$. CAR-T cells have achieved remarkable clinical outcome in the application of malignant hematological tumors, such as acute lymphoblastic leukemia (ALL) [15, 16], chronic lymphocytic leukemia (CLL) [17, 18], and non-Hodgkin lymphoma (NHL) [19]. At present, two anti-CD19 CAR-T schemes have been approved by the US Food and Drug Administration (FDA). There are Novartis's Kymriah for certain pediatric and young adult patients with a form of ALL and Gilead's Yescarta for adult patients with relapsed or refractory large B-cell lymphoma [20]. Despite the high rate of remission in hematological malignancies, there is also a high rate of relapse which remains a major issue regarding the overall efficacy of CAR-T cells therapy. Due to the poor permeability, target selection and suppressive tumor

(c) The Author(s). 2019 Open Access This article is distributed under the terms of the Creative Commons Attribution 4.0 International License (http://creativecommons.org/licenses/by/4.0/), which permits unrestricted use, distribution, and 
microenvironment etc., the clinical outcome of CAR-T cells in solid tumors is less than that in hematological tumors [21, 22]. Although the current application of CAR-T cells has made some progress, the further development of CAR-T cells has been hindered with the serious side effects of CAR-T cells. After infused with CAR-T cells, patients usually suffer some adverse reactions, the most commons of which are cytokine release storm, tumor lysis syndrome, and on-target off-tumor toxicity [23]. In an attempt to reduce these adverse effects, researchers proposed a variety of safety strategies, including suicide genes, combinatorial target-antigen recognition, synthetic Notch receptors, on-switch CAR, and inhibitory CAR. Moreover, several approaches of alleviating toxicity of CAR-T cells have been entered clinical trials (shown in Table 1). Each safety strategy of CAR-T cells has a unique mechanism of action, so they have diverse strengths and weaknesses as summarized in Table 2.

\section{Adverse effects of CAR-T cells On-target on-tumor toxicity}

The cytokine release syndrome (CRS) is the most common toxicity of CAR-T cells due to the excessive cytokine release [24]. When CAR-T cells are activated by the corresponding target cells, they release a large number of cytokines. In addition to killing tumor cells, these excessive cytokines cause various clinical symptoms, including fever, tachycardia, hypotension and hypoxia, potentially leading to rapid death [25]. As previously reported that the levels of several cytokines including tumor necrosis factor-alpha (TNF- $\alpha$ ), interferon $\gamma$ (IFN- $\gamma$ ), interleukin 6 (IL-6), and IL-10 are markedly elevated in patient serum after receiving CAR-T cells [26]. Some biomarkers, such as CAR-T cells dosage, disease burden, have been applied to predict patients' risk suffering severe CRS during CAR-T cell therapy [27]. Grading CRS can be useful to guide the management of severe CRS $[28,29]$. Furthermore, tumor lysis syndrome (TLS) is another common toxicity, especially in hematological tumors, with overlap in the symptoms of CRS. Due to the destruction of large amount of tumor cells, the rapid release of intracellular substances lead to a series of metabolic disorders such as hyperuricemia, hyperkalemia, hyperphosphatemia, hypocalcemia and metabolic acidosis, which lead to life-threatening severe arrhythmia or acute renal failure [30]. In addition to administrate high-dose corticosteroids or corresponding cytokine inhibitors (such as IL-6 receptor antagonist $\mathrm{mAb}$, tocilizumab), reducing the number of CAR$\mathrm{T}$ cells or using switchable CAR-T cells also mitigate these clinical symptoms [31].

\section{On-target off-tumor toxicity}

Because there are few available tumor-specific antigens (TSAs), the targets that recognized by CAR-T cells are always tumor-associated antigens (TAAs), which are weakly expressed in normal tissues. Therefore, the ontarget off-tumor toxicity is an unavoidable side effect. CAR-T cells have achieved promising results in hematological tumors. However, since the target antigens (CD19, CD20, CD22) are also expressed on some normal blood cells, on-target off-tumor toxicity such as B-cell aplasia become a major obstacle for application of CAR-T cells in hematological tumors [16]. In solid tumors, similar phenomena exist. As previously reported that a patient with colon cancer metastatic to the lungs and liver, experienced respiratory distress within $15 \mathrm{~min}$ after anti-ERBB2 CAR-T cells infusion. Finally, the patient still failed to survive 5 days after treatment. The final conclusion was that CAR-T cells recognized low levels of ERBB2 on lung epithelial cells [32].

\section{Other adverse effects of CAR-T cells}

Allogeneic hematopoietic stem cell transplantation (allo-HSCT) is an important treatment strategy for hematological malignancies. However, the success of allo-HSCT may be hindered by graft-versus-host disease (GVHD). Donor-derived CAR-T cells may increase the risk of GVHD occurrence. Ghosh et al. demonstrated that CAR-T cells with cumulative TCR and CAR signaling could reduce the risk of GVHD [33]. Most antigen-recognition domains of CARs derived from murine antibodies which may cause host anti-CAR response [34]. A study reported that $\mathrm{T}$ cells were armed with a CAR derived from a murine mAb against human mesothelin resulted in acute anaphylaxis due to the immunogenicity of infusion foreign proteins. Especially the transient efficacy of CAR-T cells requires repeated infusion which leads to the production of IgE antibodies [35]. Long-lived CAR-T cells or fully humanized antibodies may eliminate the anaphylaxis and immunogenicity. $T$ cells transfected with viral vectors to express antigen-specific CARs may pose a potential risk of oncogenic insertional mutagenesis. Although there was no evidence of viral vector-induced immortalization of cells, it should be noted that genotoxicity may occur in the clinical application of CAR-T cells, especially in long-term monitoring [36]. In addition, neurotoxicity was also observed during the treatment of CAR-T cells, which generally included confusion, delirium, expressive aphasia, obtundation, myoclonus, and seizure $[8,15]$. After infusion of anti-CD19 CAR-T cells, the modified $\mathrm{T}$ cells were detectable in the blood, bone marrow, and cerebrospinal fluid (CSF) of patients with neurotoxicity [7]. Furthermore, another study showed that cytokine levels including IFN- $\gamma$ and IL-6 in CSF were extremely higher than those in the serum. CAR-T cells penetrate the blood-brain barrier 


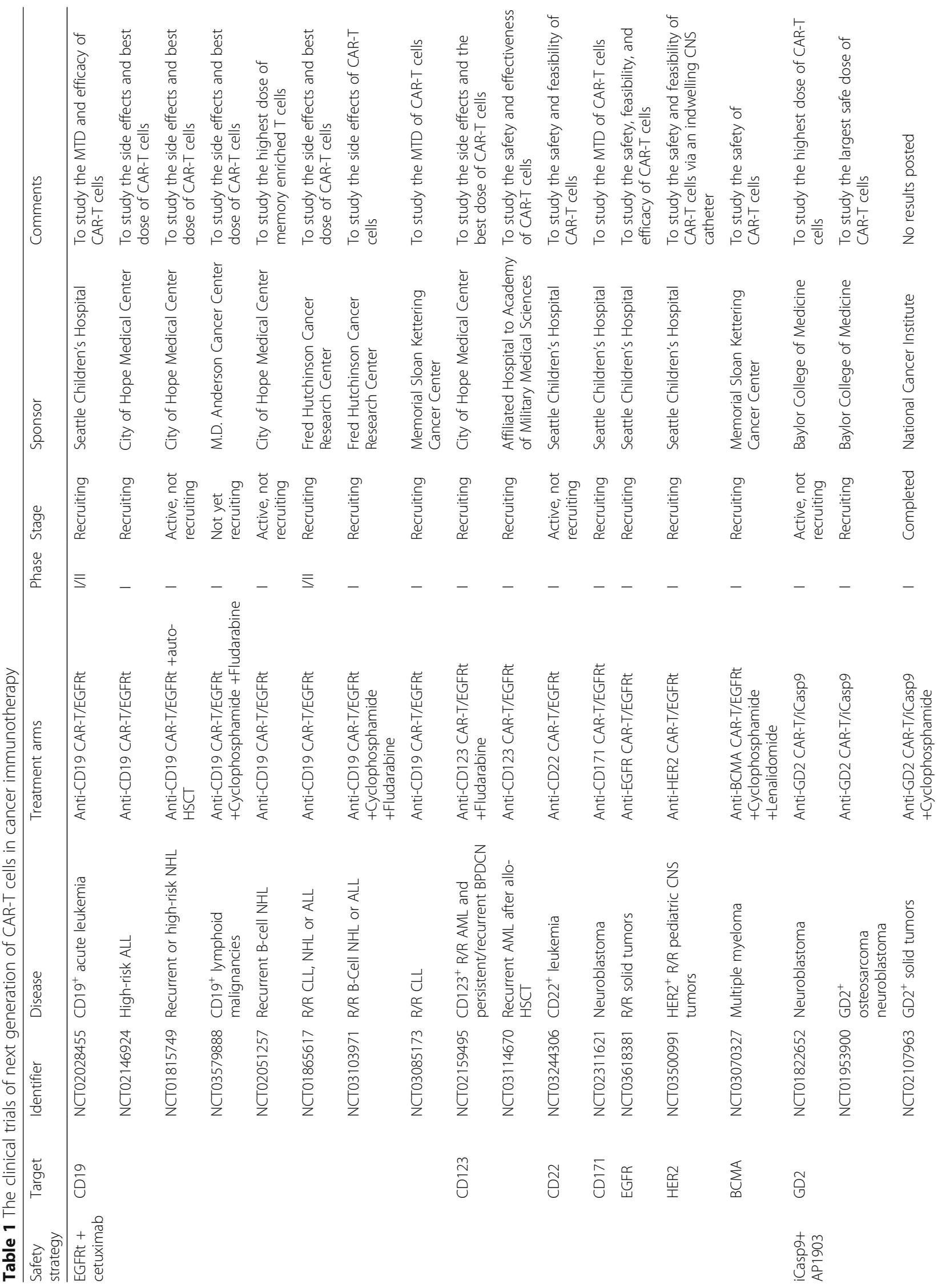




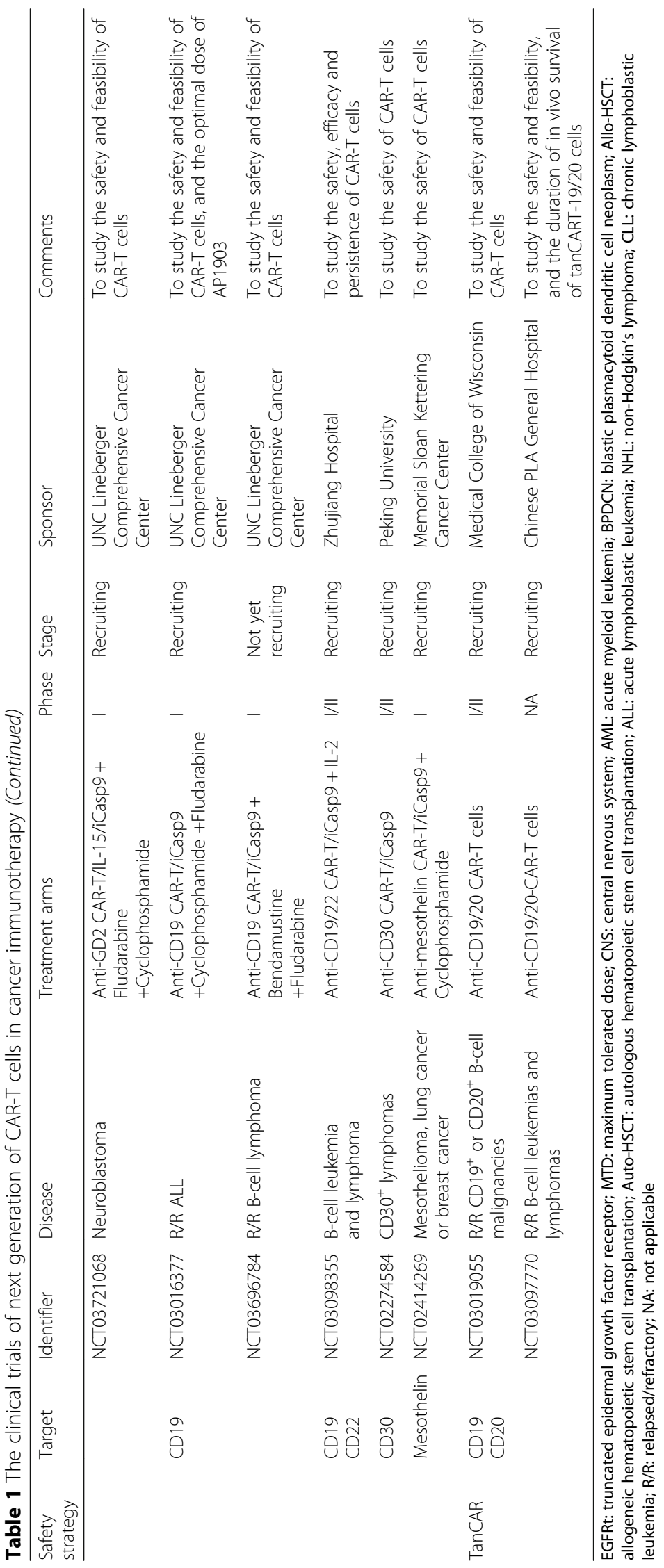


Table 2 The strengths and weaknesses of various safety strategies of CAR-T cells

\begin{tabular}{|c|c|c|c|}
\hline Safety strategy & & Strengths & Weaknesses \\
\hline \multirow[t]{4}{*}{ Suicide switch } & HSV-TK & $\begin{array}{l}\text { 1. powerful effect } \\
\text { 2. extensive clinical experience }\end{array}$ & $\begin{array}{l}\text { 1. immunogenicity } \\
\text { 2. clinical incompatibility } \\
\text { 3. slow onset } \\
\text { 4. no preventive effect for toxicity } \\
\text { 5. premature eradication of CAR-T cells }\end{array}$ \\
\hline & iCasp9 & $\begin{array}{l}\text { 1. no immunogenicity } \\
\text { 2.clinical compatibility } \\
\text { 2. rapid onset }\end{array}$ & $\begin{array}{l}\text { 1. no preventive effect for toxicity } \\
\text { 2. premature eradication of CAR-T cells }\end{array}$ \\
\hline & CD20 & $\begin{array}{l}\text { 1. no immunogenicity } \\
\text { 2. rapid onset }\end{array}$ & $\begin{array}{l}\text { 1. antibody biodistribution } \\
\text { 2. on-target toxicity from antibody } \\
\text { 3. prodrug infusion reaction } \\
\text { 4. no preventive effect for toxicity } \\
\text { 5. premature eradication of CAR-T cells }\end{array}$ \\
\hline & EGFRt & $\begin{array}{l}\text { 1. no immunogenicity } \\
\text { 2. rapid onset } \\
\text { 3. in vivo tracking }\end{array}$ & $\begin{array}{l}\text { 1. antibody biodistribution } \\
\text { 2. on-target toxicity from antibody } \\
\text { 3. prodrug infusion reaction } \\
\text { 4. no preventive effect for toxicity } \\
\text { 5. premature eradication of CAR-T cells }\end{array}$ \\
\hline \multirow[t]{3}{*}{$\begin{array}{l}\text { Endogenous } \\
\text { switch }\end{array}$} & synNotch & $\begin{array}{l}\text { 1. control the expression of the CARs } \\
\text { 2. Specific recognition of tumor sites }\end{array}$ & $\begin{array}{l}\text { 1. uncontrolled activation of CAR-T cells } \\
\text { 2. the choice of two antigens is difficult }\end{array}$ \\
\hline & iCAR & $\begin{array}{l}\text { 1. antigen-selectively regulate T cell } \\
\text { responses } \\
\text { 2. protect normal tissue from CAR-T } \\
\text { cells }\end{array}$ & $\begin{array}{l}\text { 1. uncontrolled activation of CAR-T cells } \\
\text { 2. potential "on-target, off-tumor" effect }\end{array}$ \\
\hline & $\begin{array}{l}\text { Combinatorial Target-Antigen } \\
\text { Recognition }\end{array}$ & $\begin{array}{l}\text { 1. precise killing of CAR-T cells } \\
\text { 2. overcome antigen loss }\end{array}$ & $\begin{array}{l}\text { 1. uncontrolled activation of CAR-T cells } \\
\text { 2. the choice of two antigens is difficult } \\
\text { 3. potential "on-target, off-tumor" effect }\end{array}$ \\
\hline \multirow[t]{2}{*}{$\begin{array}{l}\text { Exogenous } \\
\text { switch }\end{array}$} & Bispecific T Cell Engager & $\begin{array}{l}\text { 1. controlled activation of CAR-T cells } \\
\text { 2. simplify manufacturing of CAR-T cells }\end{array}$ & $\begin{array}{l}\text { 1. The choice of small molecules needs more } \\
\text { consideration }\end{array}$ \\
\hline & On-switch CAR & 1. controlled activation of CAR-T cells & $\begin{array}{l}\text { 1. The choice of small molecules needs more } \\
\text { consideration }\end{array}$ \\
\hline
\end{tabular}

(BBB) and produce a large number of cytokines, causing cerebral CRS [37]. Because tocilizumab or other monoclonal antibodies are incapable of passing the $\mathrm{BBB}$, corticosteroid is the drug of choice for the management of cerebral CRS [38].

\section{Safety strategies to overcome the toxicity of CAR-T cells}

Suicide gene switch

Herpes simplex virus thymidine kinase (HSV-tk) is the best characterized suicide gene [39] and widely used in combination with ganciclovir (GCV) for the treatment of a variety of malignant cancers [40, 41]. HSV-tk phosphorylates specific nucleoside analogues, such as GCV, forming toxic GCV-triphosphate compound that competes with triphosphate as a substrate incorporated into DNA via the action of DNA polymerase, leading to the inhibition of DNA synthesis and subsequent cellular death [42, 43] (Fig. 1a). The most extensive application of the HSV-tk suicide gene is to eliminate GVHD in the setting of donor lymphocyte infusion after hematopoietic stem cell transplantation (HSCT) [44, 45]. Donor T lymphocytes expressing HSV-tk suicide gene were infused into patients with leukemia after haploidentical hematopoietic stem cell transplantation (haplo-HSCT) to facilitate immune reconstitution and control GVHD $[46,47]$. HSV-tk suicide gene was also applicated in CAR-T cells targeting CD44 isoform variant 6 (CD44v6), which is overexpressed in acute myeloid leukemia (AML) and multiple myeloma (MM). The pre-clinical study indicated that anti-CD44v6 CAR-T cells expressing HSV-tk showed potent antitumor efficacy and could be effectively eliminated upon exposure to GCV [48]. Although the efficacy and feasibility of HSV-tk have been validated, there are still several limitations of HSV-tk: (1) HSV-tk is derived from virus with potential immunogenicity, therefore it may compromise the survival of functionally modified T cells [49]; (2) HSV-tk requires activation by a prodrug (like GCV) that remains a crucial pharmacologic agent for the treatment of cytomegalovirus infection [50]; (3) Because interfering DNA synthesis to induce $\mathrm{T}$ cells death is a gradual progress, it takes more time to eliminate CAR-T cells by HSV-tk [47].

The inducible safety switch caspase 9 (iCasp9) suicide gene contains a modified human caspase 9 fused to the human FK506 binding protein (FKBP). Conditional administration of a chemical inducer of dimerization (CID) (AP1903) forms dimerization and activates the 
A

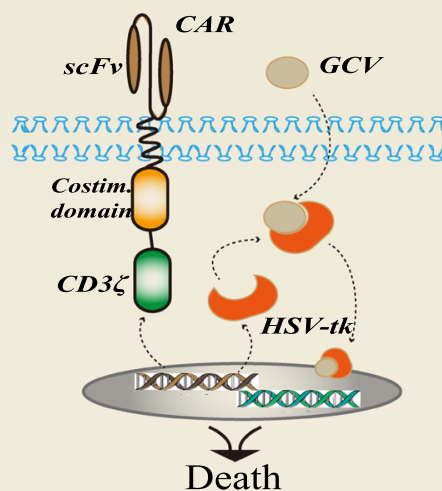

HSV-tk

D

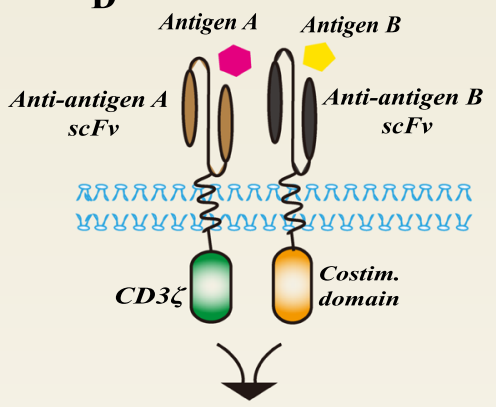

Activation
B

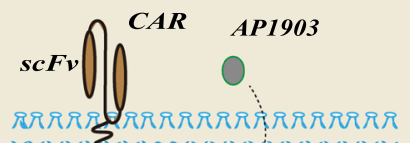

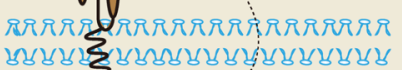

Costim.

domain

CD3द

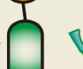

iCasp 9

Caspase 3,6,7

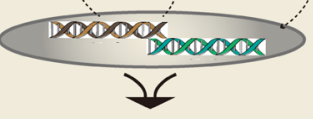

Death

iCasp9
C

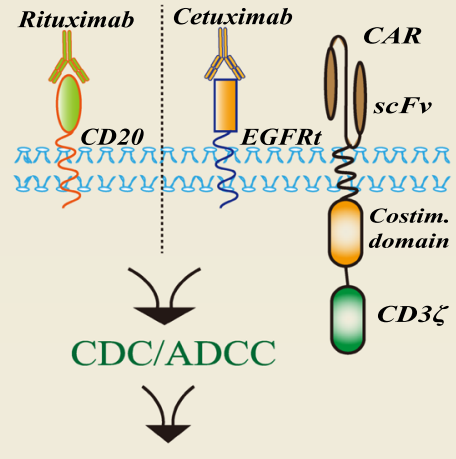

Death

\section{CD20/EGFRt}

$\mathbf{E}$

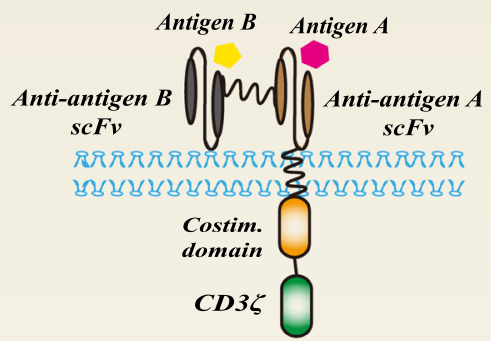

Tandem CAR
F

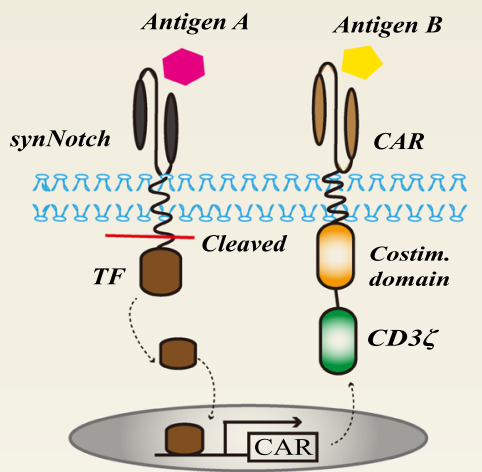

synNotch
G

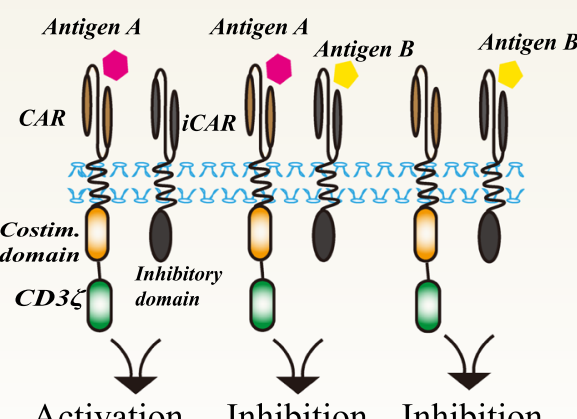

Activation Inhibition Inhibition

iCAR
H

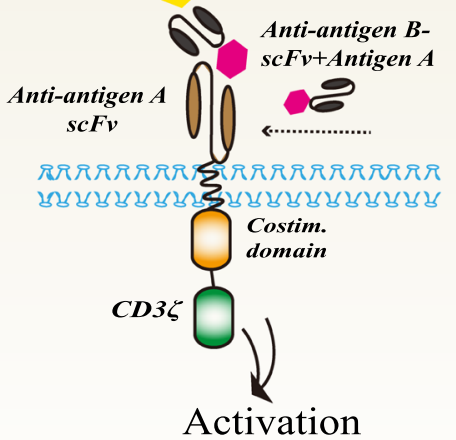

Bispecific T Cell Engager
I

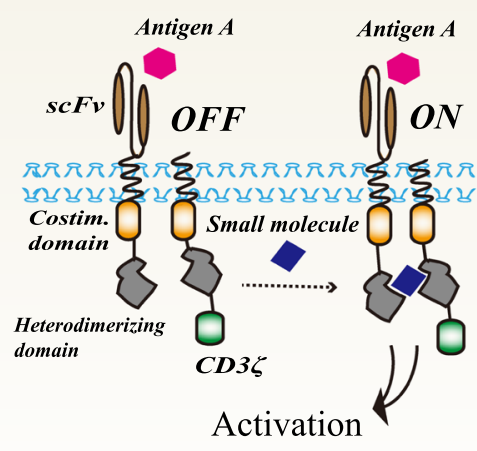

On-switch CAR

Fig. 1 (See legend on next page.) 
(See figure on previous page.)

Fig. 1 Summarized safety strategies for CAR-T cells to overcome toxicity. a HSV-tk phosphorylates GCV, forming toxic GCV-triphosphate compound that competes with triphosphate as a substrate incorporated into DNA, leading to inhibition of DNA synthesis and the cellular death. b Conditional administration of AP1903 forms dimerization with iCasp9 and activates the downstream caspase molecules, resulting in apoptosis of CAR-T cells. c CAR-T cells expressing CD20 or EGFRt could be efficiently and specifically eliminated with clinically approved monoclonal antibody rituximab or cetuximab through CDC/ADCC. $\mathbf{d}$ T cells were transduced a CAR with CD3 recognizing one antigen and a CCR with CD28 and/or 4-1BB binding another antigen. e TanCAR comprised of two tandemly linked scFvs targeting different tumor antigens coupled with one activation domain. $\mathbf{f}$ The synNotch receptor first recognized a tumor antigen, and then leading to the release of a transcriptional activator domain to drive the expression of a CAR that targeting another tumor antigen. $\mathbf{g}$ The iCAR consists of a scFv specific to the antigens expressed exclusively on normal tissue, and an inhibitory signaling domain of immunoinhibitory receptors (PD-1 and CTLA-4) to restrict T cell activity despite concurrent engagement of an activating receptors. $\mathbf{h}$ CAR-T cells do not directly recognize antigen on target cells, but they are recruited to effector cells through a bispecific small molecule. i On-switch CAR-T cells are activated by antigen recognition and a small molecule to connect the costimulatory domains and the splitting downstream ITAMs

downstream caspase molecules, resulting in apoptosis of cells expressing the fusion protein [51] (Fig. 1b). The ultimate goal of CAR-T therapy is always efficacy and safety. A second generation CAR targeting the CD19 antigen co-expressed with IL-15 and the inducible suicide gene caspase 9 (iCasp9/CAR-CD19/IL-15). IL-15 is a cytokine critical for $\mathrm{T}$ cells expansion and survival [52]. The iCasp9/CAR-CD19/IL-15 T cells showed superior survival, expansion and anti-tumor activity in vivo and in vitro compared to only CAR-CD19 T cells. And more importantly, the incorporation of iCasp9 suicide gene and its pharmacologic activation efficiently eliminated these gene engineered $\mathrm{T}$ cells. The administration of iCasp9 suicide gene further increased the safety of the proposed approach and its potential clinical applicability [53]. A third generation anti-CD20 CAR-T cells containing both CD28 and 4-1BB co-stimulatory domains were transduced with iCasp9 suicide gene and a truncated CD19 ( $\triangle$ CD19) selectable marker. The iCasp9/CARCD20/ $\triangle$ CD19 $T$ cells caused effective cytotoxicity to CD20-positive tumor cells and induced potent cytokines secretion. 20 nM AP1903 eliminated 90\% of the transduced T cells within $24 \mathrm{~h}$ and $98 \%$ were dead after $72 \mathrm{~h}$. In addition, the CID treatment has no impact on the growth of non-transduced $\mathrm{T}$ cells even at concentrations as high as $200 \mathrm{nM}$ [54]. Long-term B cell aplasia is one of the manifestations of "on-target off-tumor" toxicity for the application of anti-CD19 CAR-T cells in B cell lymphoid malignancies, which strongly correlated with long-term survival [55]. The anti-CD19 CAR-T cells incorporated with iCasp9 suicide gene and a truncated nerve growth factor receptor ( $\triangle \mathrm{NGFR})$ as selective marker exhibited potent cytotoxic activity against CD19positive tumor cells in vitro. In a humanized mouse model, the iCasp9 safety switch efficiently eliminated anti-CD19 CAR-T cells in a dose-dependent manner, allowing normal B cell reconstitution [56]. CD33 is overexpressed on the cell surface of $90 \%$ of AML blasts [57]. However, it is also expressed on multipotent myeloid precursors [58]. iCasp9 suicide gene and $\triangle \mathrm{CD} 19$ modified CD33 CAR-T cells (iCasp9/CAR CD33/ $\triangle$ CD19) not only are cytotoxic to CD33-positive tumor cells but also could be used as a "bridge" therapy for patients coming to allo-HSCT. Due to a proportion of the infused CD34 ${ }^{+}$ hematopoietic stem cells also express CD33, it is essential to completely eliminate the CD33 CAR-T cells prior to stem cell infusion to reduce the potential risk of engraftment failure. The conditional administration of CID resulted in the elimination of only $76.4 \%$ anti-CD33 CAR-T cells [59]. Previous study demonstrated that iCasp9 resistant cells expressed higher anti-apoptotic molecule B-cell lymphoma 2 (BCL-2) [60]. Therefore, the co-administration of suicide gene/CID and BCL-2 inhibitor resulted in additive effect up to completely cell elimination [59]. Another iCasp9 engineered CAR-T cells targeting interleukin-1 receptor accessory protein (IL-1RAP) which is expressed by chronic myeloid leukemia (CML) but not the normal $\mathrm{CD}_{3} 4^{+}$ hematopoietic stem cell [61] showed cytotoxicity against IL-1RAP-positive cell lines or primary CML cells and induced secretion of pro-inflammatory cytokines in vitro and in vivo. In the NSG murine model, $87 \%$ of anti-IL1RAP CAR-T cells were eliminated after intraperitoneal injection of AP1903, but control T cells were not affected [62]. iCasp9 suicide gene as a T-cell safety switch also has been entered clinical trials. Haplo-HSCT is an alternative therapeutic strategy for patients without a more closely matched donor or who need an urgent allo-HSCT [63]. However, patients are more prone to occur GVHD after transplantation, mainly due to the existence of the non-shared HLA haplotype [64]. Adoptive transfer of donor derived engineer iCasp9-T cells may promote immune reconstitution and reduce the risk of uncontrolled GVHD. In a phase I trial (NCT00710892), genetically modified iCasp9/ $\triangle \mathrm{CD} 19 \mathrm{~T}$ cells were infused into five patients that had undergone haploidentical transplantation for relapsed acute leukemia. Four patients developed into GVHD after the infusion of allodepleted $\mathrm{T}$ cells were treated with a single dose $(0.4 \mathrm{mg} /$ $\mathrm{kg}$ ) of AP1903. More than 90\% transgenic T cells were eliminated within $30 \mathrm{~min}$ after administration of AP1903. GVHD-associated manifestations of skin and 
liver started to alleviate within $24 \mathrm{~h}$ [65]. Long-term follow-up (more than 2 years) results showed that the iCasp9 suicide gene not only permanently controlled GVHD, but also contributed to improve recovery of immune $\mathrm{T}$ cell to control opportunistic infections after haplo-HSCT [66]. In addition, another similar clinical trial (NCT01494103) results suggested that iCasp9-T cells reconstituted immunity posttransplant and provided protection from EBV, CMV, HHV6, VZV and BKV infections. Administration of AP1903 eliminated iCasp9-T cells from peripheral blood (PB) and the central nervous system (CNS) leading to the rapid remission of GVHD and CRS [67]. The humanized iCasp9 suicide gene did not caused immunogenicity, thus avoiding the attack from host immunity to engineered CAR-T cells. Moreover, non-toxic exogenous small molecule drug and rapid induction of apoptosis make iCasp9 to be a better option of safety method of CAR-T cells.

$\mathrm{T}$ cells modified to co-express the CAR and CD20 or truncated epidermal growth factor receptor (EGFRt) could be efficiently and specifically eliminated with clinically approved monoclonal antibody rituximab or cetuximab through the complement dependent cytotoxicity (CDC) and antibody-dependent cell-mediated cytotoxicity (ADCC) [68, 69] (Fig. 1c). In particular, EGFRt-rituximab suicide switch has been incorporated into the CAR-T cells to mitigate toxicity in numerous clinical trials, which were summarized in Table 1. Although antibody-mediated suicide switch showed significant effects in controlling the toxicity of engineered CAR-T cells in preclinical and clinical studies [70, 71], the biodistribution of therapeutic antibodies and possible damage to normal tissues expressing the specific proteins may limit the further development [72].

\section{Combinatorial target-antigen recognition}

Dividing the traditional CAR into two complementary parts may be a promising approach to enhance safety. $\mathrm{T}$ cells were transduced a $\mathrm{CAR}$ with $\mathrm{CD} 3 \zeta$ recognizing one antigen and a chimeric costimulatory receptor (CCR) with $\mathrm{CD} 28$ and/or 4-1BB binding another antigen (Fig. 1d). Based on the strategy, combinatorial using the prostate-specific membrane antigen (PSMA) and prostate stem cell antigen (PSCA), Klossetal et al. developed the co-transduced CAR-T cells and demonstrated that the $\mathrm{T}$ cells efficiently eliminated tumors that express both antigens but did not affect tumors expressing either antigen alone. Moreover, their results showed that $\mathrm{T}$ cells expressing suboptimal activation CAR (low affinity) and a CCR are sufficiently activated by $\mathrm{PSMA}^{+} \mathrm{PSCA}^{+}$but not $\mathrm{PSMA}^{+} \mathrm{PSCA}^{-}$target cells. However, when $\mathrm{T}$ cells transduced efficient activation CAR (high affinity) and a CCR recirculate, they could kill the $\mathrm{PSMA}^{+} \mathrm{PSCA}^{-}$target cells without requiring further costimulation, resulting in an "ontarget off-tumor" adverse effect on normal tissues [73]. Another study reported a combinatorial targetantigen recognition CAR strategy that activation receptor with $\mathrm{CD} 3 \zeta$ against mesothelin is physically dissociated from CCR with $\mathrm{CD} 28$ against a-folate receptor (FRa). The dual-targeting CAR-T cells exhibited significant cytotoxicity to ovarian cancer cells expressing two antigens in vitro and in pre-clinical animal studies and coupled with minimized damage to normal tissues [74]. Wilkie et al. also designed the "dual-targeted" $\mathrm{T}$ cells co-expressing an ERBB2- and MUC1-specific CAR that signal using $\mathrm{CD} 3 \zeta$ and CD28 respectively. However, these dual CAR-T cells only eliminated ERBB2 $^{+}$tumor cells, and produced modest IL-2 in response to co-stimulation with a second antigen when compared to a control CAR-T

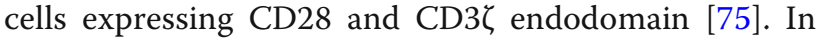
addition, two tandem linked scFvs targeting different tumor antigens coupled with one activation domain forming a CAR called tandem CAR (TanCAR) [76] (Fig. 1e). Studies demonstrated that TanCAR T cells exhibited significant cytotoxicity to glioblastoma (HER2/IL13R $\alpha)$ and leukemia (CD19/CD133) in vitro and in vivo $[77,78]$. $T$ cells expressing TanCAR simultaneously recognized two different antigens on tumor cells, which reduced antigen escape and enhanced antitumor efficacy, as well as mitigated "on-target off-tumor" toxicity $[79,80]$. However, it is highly dependent on the two targeted antigens that uniformly expressed in a particular cancer type, but expressed differentially and at low levels in normal tissues.

\section{Synthetic notch receptors}

A recently study reported a novel class of modular receptors called synthetic Notch (synNotch) receptors [81]. Wild-type Notch protein contains three parts: an extracellular ligand-binding domain, a transmembrane domain, releasing transcriptional regulator through ligand-induced cleavage, and the intracellular effector domain [82]. The extracellular recognition domain could be customized with antibody-based domain, such as single-chain antibody or nanobodies, to recognize specific antigens. Moreover, the intracellular transcription domain could be replaced to activate downstream interesting target genes. Therefore, the modified synNotch receptors only retain the core portion of the transmembrane region of wild-type Notch, which mediates proteolysis [81]. Based on the mechanism, Roybal et al. designed the synNotch AND-gate circuits for the safety of CAR-T cells. The synNotch receptor first recognized a tumor antigen, and then leading to the release of a transcriptional activator domain to drive the expression of a CAR that targeting another tumor antigen (Fig. 1f). 
Jurkat T cells engineering with synNotch receptor recognized CD19 and mesothelin effectively killed tumor cells that expressing two antigens but not one of these antigens. The synNotch AND-gate was tested in the primary $\mathrm{T}$ cells binding green fluorescent protein (GFP) and a CAR against CD19. The results indicated that the synNotch AND-gate T cells could selectively clear the dual antigens tumor in vivo, while avoiding the by-stander tissues [83]. Receptor tyrosine kinase-like orphan receptor 1 (ROR1) is expressed by many epithelial tumors and stromal cells. Targeting ROR1 not only will lyse ROR1+ tumor cells, but also cause toxicity on the ROR1+ normal tissues [84]. Targeting ROR1 CAR-T cells are engineered with synNotch receptors specific for EPCAM or B7-H3. The CAR-T cells showed selective cytotoxicity to ROR1+ tumor cells, but not ROR1+ stromal cells. According to the results, $\mathrm{B} 7-\mathrm{H} 3$ is a more suitable synNotch target due to the more frequent co-expression with ROR1 on cancers than EPCAM [85]. In addition, SynNotch $\mathrm{T}$ cells could be engineered to deliver cytokines, antibodies, or small molecules in response to antigens and remodel local microenvironments in a very precise and localized way [86].

\section{Inhibitory chimeric antigen receptor}

Immune inhibitory receptors, such as PD-1, CTLA-4, play a crucial role in the regulation of immune response, especially in attenuating or terminating $\mathrm{T}$ cells response [87]. It is a promising approach that applying inhibitory receptors to CAR-T cells as a safety strategy. Fedorov et al. designed the PD-1- and CTLA-4-based inhibitory chimeric antigen receptor (iCAR) targeting PSMA. The iCAR consists of a scFv specific to the antigens expressed exclusively on normal tissue, and a powerful acute inhibitory signaling domain of immunoinhibitory receptors (PD-1 and CTLA-4) to restrict $\mathrm{T}$ cell activity despite concurrent engagement of an activating receptors (Fig. 1g). The iCAR showed antigen-specific suppression of $\mathrm{T}$ cell cytokine secretion, cytotoxicity, and proliferation in a temporary and reversible manner [88]. iCAR provides a dynamic, self-regulating safety switch to prevent the on target off-tumor side effects. However, iCAR T cells need to recognize tissue-specific antigens that are absent or down-regulated on tumors but expressed by the off-target tissues. And iCAR T cells cannot control their spatiotemporal activity.

\section{Bispecific $T$ cell engager}

$\mathrm{T}$ cells were engineered to express a CAR that binds a fluorescein isothiocyanate (FITC) molecule, termed "universal" anti-FITC-directed CAR-T cell. These CAR-T cells do not directly recognize antigen on target cells, but they are recruited to effector cells through a bispecific small molecule (Fig. 1h). Therefore, in the absence of bispecific small molecules, these CAR-T cells are inactive against normal tissues. The folate-FITC conjugate, as a bispecific small molecule switch, redirects and regulates anti-FITC-CAR-T cells activity to target folate receptor positive tumor cells in a specific and dosedependent manner [89]. Various antitumor antibodies (Ab), such as cetuximab (Ctx; anti-EGFR), trastuzumab (anti-Her2), and rituximab (Rtx; anti-CD20), were conjugated with FITC forming bispecific small molecule AbFITC, which redirected anti-FITC-CAR-T cells binding to tumor cells and induced antitumor activity in vitro and in vivo [90]. Additionally, the antitumor effects of anti-FITC-CAR-T cells also confirmed in CD19- and CD22-expressing cancer cells. The Ab-FITC selectively led CAR-T cells to target cells and promoted the cytokine secretion that correlated with the degree of cytotoxicity [91]. Rodgers et al. developed the recombinant antibody-based bifunctional switches that consists of a specific anti-tumor antigen Fab molecule conjugated with a peptide neo-epitope (PNE) and a peptide-specific switchable CAR-T (sCAR-T) cell. The study indicated that SCAR-T cells provided equal lysis efficacy and lower cytokine levels compared to conventional anti-CD19 CAR-T cells in the presence of anti-CD19 Fab-PNE. Similarly, sCAR-T cells together with anti-CD20 FabPNE are suitable to eradicate CD20-positive tumor cells through the selective formation of immunological synapses [91]. T cells were modified to express a chimeric receptor $\mathrm{CD} 16 \mathrm{~V}-\mathrm{BB}-\zeta$ that included the high-affinity CD16 (FCGR3A) V158 variant, CD8a hinge, and transmembrane domains, as well as $\mathrm{CD} 3 \zeta$ and $4-1 \mathrm{BB}$. The CD16V-BB- $\zeta \mathrm{T}$ cells recognized Fc fragment of specific antibody that targeting tumor antigens and prompted the capacity to exert ADCC. Antibody binding to the CD16V-BB- $\zeta$ receptor triggered T-cell activation, proliferation and specific cytotoxicity against target cells. Moreover, cytotoxicity was completely relied on the presence of a specific antibody binding to target cells. Dissociating antibodies neither provoke nonspecific cytotoxicity nor affected specific cytotoxicity [92]. The activity of anti-tag CAR-T cells could be attenuated by reducing the administration of bispecific small molecule when the adverse effects occur. Therefore, the bispecific $\mathrm{T}$ cell engager is used as a safety strategy of CAR-T cells due to the controllability.

\section{On-switch CAR}

On-switch CAR consists of an extracellular specific antigen-binding domain $(\mathrm{scFv})$ with costimulatory domains and a key downstream signaling element: the ITAMs from the $\mathrm{T}$ cell receptor $\mathrm{CD} 3 \zeta$ subunit [93] (Fig. 1i). Recognition of the cognate antigen and application of a priming small molecule trigger the therapeutic activity of engineered-T cells, neither small molecule 
nor antigen should activate it alone. The small molecule-dependent on-switch approach precisely control the timing, location, and dosage of $\mathrm{T}$ cell activity in a titratable and reversible manner, thereby alleviating toxicity [94]. Juillerat et al. developed a "transient CAR-T cell" strategy, which dimerized at the hinge domain with the addition of a small molecule, thereby endowed the state of CAR-T cells from off to on. The engineered CAR-T cells presented a significant cytolytic activity only in presence of the AP21967, and reaction intensity was dependent on the amount of small molecule [95].

\section{Other strategies}

In addition to the above superior safety strategies, other methods may also reduce the side effects of CAR-T cells. Regional delivery or intratumoral injection of CAR- $\mathrm{T}$ cells could be considered as a measure of reducing "offtumor on-target" toxicity and enhancing antitumor efficacy [96-98]. A large number of activated CAR-T cells and lysed tumor cells will cause CRS and TLS. Transient CAR expression may be an available precaution to reduce these toxicities, which avoids the excessive reactivity of CAR-T cells [99]. Engineered T cells expressing a fully human CAR targeting the human C4 folate receptor-alpha $(\alpha F R)$ with an intermediate affinity can efficiently eliminate $\alpha F R$-expressing tumors in vitro and in vivo. The CAR-T cells may overcome issues of transgene immunogenicity and less recognition of normal cells expressing low levels of $\alpha \mathrm{FR}$ that mitigate "on-target off-tumor" toxicity [100]. CAR-T cells with decreased affinity to ErbB2 could discriminate tumor cells with high and low level ErbB2 from normal cells with physiologic level ErbB2 [101]. Other studies also demonstrated that low-affinity CAR-T cells targeting EGFR or CD123 could distinguish malignant from normal cells and reduce the "off-tumor on-target" toxicity [102, 103]. Moreover, some symptomatic treatments, such as cytokine-blocking agents and high-dose corticosteroids have also played a role in reducing the adverse effects of CAR-T cells [104, 105].

\section{Conclusion and perspectives}

Adoptive cellular therapy with the engineered CAR-T cells is a promising approach for cancer treatment. And encouraging results have been achieved in hematological malignancies. But the toxicity of CAR-T cells has been a challenge and impedes the further development. Nowadays, numerous safety measures to overcome these adverse effects of CAR-T cells have been investigated in preclinical and clinical trials. Traditional suicide genes can quickly and effectively mitigate toxicity, but they also irreversibly eliminate therapeutic CAR-T cells which are expensive labor-intensive. Endogenous switches including synNotch, iCAR and CCR can cause intracellular regulation in a self-switch manner when CAR-T cells recognize responding antigens, which significantly reduce on-target off-tumor effects. However, these methods cannot control the timing and intensity of CAR-T cells activity. Bispecific $T$ cell engager and onswitch CAR could achieve it by exogenously administrating small molecules. Of course, the exogenous small molecules should be safe and bio-inert, as well as have good pharmacokinetic properties. Although these strategies have potential shortcomings and need improvement or optimized new methods, we believe that the next generation CAR-T cells with safety switch could exhibit superior safety and efficacy, as well as bring more hopes to patients with malignant tumors.

\section{Abbreviations}

ACT: adoptive cell therapy; ADCC: antibody-dependent cell-mediated cytotoxicity; ALL: acute lymphoblastic leukemia; allo-HSCT: allogeneic hematopoietic stem cell transplantation; AML: acute myeloid leukemia; BBB: blood-brain barrier; BCL-2: B-cell lymphoma 2; CAR-T: chimeric antigen receptor T; CCR: chimeric costimulatory receptor; $\mathrm{CD} 3 \mathrm{C}_{\text {: }} \mathrm{CD} 3$ zeta chain;

CD44v6: CD44 isoform variant 6; CDC: complement dependent cytotoxicity; CID: chemical inducer of dimerization; CLL: chronic lymphocytic leukemia; CML: chronic myeloid leukemia; CNS: central nervous system; CRS: cytokine release syndrome; CSF: cerebrospinal fluid; EGFRt: truncated epidermal growth factor receptor; FDA: Food and Drug Administration; FITC: fluorescein isothiocyanate; FKBP: FK506 binding protein; FRa: a-folate receptor; GCV: ganciclovir; GVHD: graft-versus-host disease; haplo-HSCT: haploidentical hematopoietic stem cell transplantation; HSV-tk: herpes simplex virus thymidine kinase; iCAR: inhibitory chimeric antigen receptor;

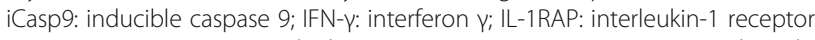
accessory protein; IL-6: interleukin 6; ITAMs: immunoreceptor tyrosine-based activation motifs; MHC: major histocompatibility complex; MM: multiple myeloma; NHL: non-Hodgkin lymphoma; PB: peripheral blood; PNE: peptide neo-epitope; PSCA: prostate stem cell antigen; PSMA: prostate-specific membrane antigen; ROR1: receptor tyrosine kinase-like orphan receptor 1; sCAR-T: switchable CAR-T; scFv: single-chain variable fragment; synNotch: synthetic Notch; TAAs: tumor-associated antigens; TanCAR: tandem CAR; TLS: tumor lysis syndrome; TNF-a: tumor necrosis factor-alpha; TSAs: tumor-specific antigens; $\triangle N G F R$ : truncated nerve growth factor receptor

\section{Acknowledgements}

Not applicable.

\section{Authors' contributions}

SY performed the selection of literature, drafted the manuscript and prepared the Figs. MY and SQ collected the related references and revised the language. KW carried out the design of this review and revised the manuscript. All authors contributed to this manuscript. All authors read and approved the final manuscript.

\section{Funding}

This work was supported by the National Natural Science Foundation of China (NSFC) No. 81572608, 81874120 and Wuhan Science and Technology Bureau No. 2017060201010170 (KW).

\section{Availability of data and materials}

Data sharing not applicable to this article as no datasets were generated or analyzed during the current study.

Ethics approval and consent to participate Not applicable.

Consent for publication

Not applicable. 


\section{Competing interests}

The authors declare that they have no competing interests.

Received: 1 May 2019 Accepted: 14 August 2019 Published online: 20 August 2019

\section{References}

1. Chen DS, Mellman I. Elements of cancer immunity and the cancer-immune set point. Nature. 2017;541(7637):321-30.

2. Flint TR, Fearon DT, Janowitz T. Connecting the metabolic and immune responses to Cancer. Trends Mol Med. 2017;23(5):451-64.

3. Yu S, Li A, Liu Q, Li T, Yuan X, Han X, et al. Chimeric antigen receptor T cells: a novel therapy for solid tumors. J Hematol Oncol. 2017;10(1):78.

4. Yu S, Li A, Liu Q, Yuan X, Xu H, Jiao D, et al. Recent advances of bispecific antibodies in solid tumors. J Hematol Oncol. 2017;10(1):155.

5. Poggio M, Hu T, Pai CC, Chu B, Belair CD, Chang A, et al. Suppression of Exosomal PD-L1 Induces Systemic Anti-tumor Immunity and Memory. Cell. 2019;177(2):414-427.e413.

6. Yi M, Yu S, Qin S, Liu Q, Xu H, Zhao W, et al. Gut microbiome modulates efficacy of immune checkpoint inhibitors. J Hematol Oncol. 2018;11(1):47.

7. Maude SL, Frey N, Shaw PA, Aplenc R, Barrett DM, Bunin NJ, et al. Chimeric antigen receptor T cells for sustained remissions in leukemia. N Engl J Med. 2014;371(16):1507-17.

8. Lee DW, Kochenderfer JN, Stetler-Stevenson M, Cui YK, Delbrook C, Feldman SA, et al. T cells expressing CD19 chimeric antigen receptors for acute lymphoblastic leukaemia in children and young adults: a phase 1 doseescalation trial. Lancet. 2015;385(9967):517-28.

9. Maher J, Wilkie S, Davies DM, Arif S, Picco G, Julien S, et al. Targeting of tumor-associated Glycoforms of MUC1 with CAR T cells. Immunity. 2016;45(5):945-6.

10. Fesnak $A D$, June $C H$, Levine $B L$. Engineered $T$ cells: the promise and challenges of cancer immunotherapy. Nat Rev Cancer. 2016;16(9):566-81.

11. Finney HM, Akbar AN, Lawson AD. Activation of resting human primary $T$ cells with chimeric receptors: costimulation from CD28, inducible costimulator, CD134, and CD137 in series with signals from the TCR zeta chain. J Immunol. 2004;172(1):104-13.

12. Di S, Li Z. Treatment of solid tumors with chimeric antigen receptorengineered T cells: current status and future prospects. Sci China Life Sci. 2016;59(4):360-9.

13. Chmielewski M, Hombach AA, Abken H. Of CARs and TRUCKs: chimeric antigen receptor (CAR) T cells engineered with an inducible cytokine to modulate the tumor stroma. Immunol Rev. 2014;257(1):83-90.

14. Chmielewski M, Abken H. TRUCKs: the fourth generation of CARs. Expert Opin Biol Ther. 2015;15(8):1145-54.

15. Davila ML, Riviere I, Wang X, Bartido S, Park J, Curran K, et al. Efficacy and toxicity management of 19-28z CAR T cell therapy in B cell acute lymphoblastic leukemia. Sci Transl Med. 2014;6(224):224ra225.

16. Grupp SA, Kalos M, Barrett D, Aplenc R, Porter DL, Rheingold SR, et al. Chimeric antigen receptor-modified T cells for acute lymphoid leukemia. N Engl J Med. 2013;368(16):1509-18.

17. Porter DL, Hwang WT, Frey NV, Lacey SF, Shaw PA, Loren AW, et al. Chimeric antigen receptor T cells persist and induce sustained remissions in relapsed refractory chronic lymphocytic leukemia. Sci Transl Med. 2015;7(303):303ra139.

18. Porter DL, Levine BL, Kalos M, Bagg A, June CH. Chimeric antigen receptormodified T cells in chronic lymphoid leukemia. N Engl J Med. 2011;365(8):725-33.

19. Kochenderfer JN, Dudley ME, Kassim SH, Somerville RP, Carpenter RO, Stetler-Stevenson M, et al. Chemotherapy-refractory diffuse large B-cell lymphoma and indolent B-cell malignancies can be effectively treated with autologous T cells expressing an anti-CD19 chimeric antigen receptor. J Clin Oncol. 2015;33(6):540-9.

20. Leyfman Y. Chimeric antigen receptors: unleashing a new age of anticancer therapy. Cancer Cell Int. 2018;18(182).

21. Schubert ML, Hoffmann JM, Dreger P, Muller-Tidow C, Schmitt M. Chimeric antigen receptor transduced T cells: tuning up for the next generation. Int J Cancer. 2018;142(9):1738-47.

22. Beatty GL, O'Hara M. Chimeric antigen receptor-modified T cells for the treatment of solid tumors: Defining the challenges and next steps. Pharmacol Ther. 2016;166(30-39).
23. Sun S, Hao H, Yang G, Zhang Y, Fu Y. Immunotherapy with CAR-Modified T Cells: Toxicities and Overcoming Strategies. J Immunol Res. 2018; 2018(2386187).

24. Lee DW, Gardner R, Porter DL, Louis CU, Ahmed N, Jensen M, et al. Current concepts in the diagnosis and management of cytokine release syndrome. Blood. 2014;124(2):188-95.

25. Hay KA, Hanafi LA, Li D, Gust J, Liles WC, Wurfel MM, et al. Kinetics and biomarkers of severe cytokine release syndrome after CD19 chimeric antigen receptor-modified T-cell therapy. Blood. 2017;130(21):2295-306.

26. Fitzgerald JC, Weiss SL, Maude SL, Barrett DM, Lacey SF, Melenhorst JJ, et al. Cytokine release syndrome after chimeric antigen receptor T cell therapy for acute lymphoblastic leukemia. Crit Care Med. 2017;45(2):e124-31.

27. Wang Z, Han W. Biomarkers of cytokine release syndrome and neurotoxicity related to CAR-T cell therapy. Biomark Res. 2018;6(40).

28. Liu D, Zhao J. Cytokine release syndrome: grading, modeling, and new therapy. J Hematol Oncol. 2018;11(1):121.

29. Porter D, Frey N, Wood PA, Weng Y, Grupp SA. Grading of cytokine release syndrome associated with the CAR T cell therapy tisagenlecleucel. J Hematol Oncol. 2018;11(1):35.

30. Howard SC, Jones DP, Pui CH. The tumor lysis syndrome. N Engl J Med. 2011;364(19):1844-54

31. De Benedetti F, Brunner HI, Ruperto N, Kenwright A, Wright S, Calvo I, et al. Randomized trial of tocilizumab in systemic juvenile idiopathic arthritis. N Engl J Med. 2012;367(25):2385-95.

32. Morgan RA, Yang JC, Kitano M, Dudley ME, Laurencot CM, Rosenberg SA. Case report of a serious adverse event following the administration of T cells transduced with a chimeric antigen receptor recognizing ERBB2. Mol Ther. 2010;18(4):843-51.

33. Ghosh A, Smith M, James SE, Davila ML, Velardi E, Argyropoulos KV, et al. Donor CD19 CAR T cells exert potent graft-versus-lymphoma activity with diminished graft-versus-host activity. Nat Med. 2017;23(2):242-9.

34. Curran KJ, Pegram HJ, Brentjens RJ. Chimeric antigen receptors for T cell immunotherapy: current understanding and future directions. J Gene Med. 2012;14(6):405-15.

35. Maus MV, Haas AR, Beatty GL, Albelda SM, Levine BL, Liu X, et al. T cells expressing chimeric antigen receptors can cause anaphylaxis in humans. Cancer Immunol Res. 2013;1(1):26-31.

36. Scholler J, Brady TL, Binder-Scholl G, Hwang WT, Plesa G, Hege KM, et al. Decade-long safety and function of retroviral-modified chimeric antigen receptor T cells. Sci Transl Med. 2012;4(132):132ra153.

37. Hu Y, Sun J, Wu Z, Yu J, Cui Q, Pu C, et al. Predominant cerebral cytokine release syndrome in $C D 19$-directed chimeric antigen receptor-modified T cell therapy. J Hematol Oncol. 2016;9(1):70.

38. Mei H, Jiang $H$, Wu Y, Guo T, Xia L, Jin R, et al. Neurological toxicities and coagulation disorders in the cytokine release syndrome during CAR-T therapy. Br J Haematol. 2018;181(5):689-92.

39. Vassaux G, Martin-Duque P. Use of suicide genes for cancer gene therapy: study of the different approaches. Expert Opin Biol Ther. 2004;4(4):519-30.

40. Moolten FL, Wells JM. Curability of tumors bearing herpes thymidine kinase genes transferred by retroviral vectors. J Natl Cancer Inst. 1990;82(4):297-300.

41. Sangro B, Mazzolini G, Ruiz M, Ruiz J, Quiroga J, Herrero I, et al. A phase I clinical trial of thymidine kinase-based gene therapy in advanced hepatocellular carcinoma. Cancer Gene Ther. 2010;17(12):837-43.

42. Matthews T, Boehme R. Antiviral activity and mechanism of action of ganciclovir. Rev Infect Dis. 1988;10 Suppl 3(S490-494).

43. Moolten FL. Tumor chemosensitivity conferred by inserted herpes thymidine kinase genes: paradigm for a prospective cancer control strategy. Cancer Res. 1986;46(10):5276-81.

44. Bonini C, Ferrari G, Verzeletti S, Servida P, Zappone E, Ruggieri L, et al. HSVTK gene transfer into donor lymphocytes for control of allogeneic graftversus-leukemia. Science. 1997;276(5319):1719-24.

45. Ciceri F, Bonini C, Marktel S, Zappone E, Servida P, Bernardi M, et al. Antitumor effects of HSV-TK-engineered donor lymphocytes after allogeneic stem-cell transplantation. Blood. 2007;109(11):4698-707.

46. Ciceri F, Bonini C, Stanghellini MT, Bondanza A, Traversari C, Salomoni M, et al. Infusion of suicide-gene-engineered donor lymphocytes after family haploidentical haemopoietic stem-cell transplantation for leukaemia (the TK007 trial): a non-randomised phase I-II study. Lancet Oncol. 2009;10(5):489-500.

47. Tiberghien P, Ferrand C, Lioure B, Milpied N, Angonin R, Deconinck E, et al. Administration of herpes simplex-thymidine kinase-expressing donor $\mathrm{T}$ cells with a T-cell-depleted allogeneic marrow graft. Blood. 2001;97(1):63-72. 
48. Casucci M, Falcone L, Camisa B, Norelli M, Porcellini S, Stornaiuolo A, et al. Extracellular NGFR Spacers Allow Efficient Tracking and Enrichment of Fully Functional CAR-T Cells Co-Expressing a Suicide Gene. Front Immunol. 2018;9(507).

49. Berger C, Flowers ME, Warren EH, Riddell SR. Analysis of transgene-specific immune responses that limit the in vivo persistence of adoptively transferred HSV-TK-modified donor T cells after allogeneic hematopoietic cell transplantation. Blood. 2006;107(6):2294-302.

50. Lupo-Stanghellini MT, Provasi E, Bondanza A, Ciceri F, Bordignon C, Bonini C. Clinical impact of suicide gene therapy in allogeneic hematopoietic stem cell transplantation. Hum Gene Ther. 2010;21(3):241-50.

51. Gargett T, Brown MP. The inducible caspase- 9 suicide gene system as a "safety switch" to limit on-target, off-tumor toxicities of chimeric antigen receptor T cells. Front Pharmacol. 2014;5(235).

52. Ma $A$, Koka R, Burkett $P$. Diverse functions of IL-2, IL-15, and IL-7 in lymphoid homeostasis. Annu Rev Immunol. 2006;24(657-679).

53. Hoyos V, Savoldo B, Quintarelli C, Mahendravada A, Zhang M, Vera J, et al. Engineering CD19-specific T lymphocytes with interleukin-15 and a suicide gene to enhance their anti-lymphoma/leukemia effects and safety. Leukemia. 2010;24(6):1160-70.

54. Budde LE, Berger $C$, Lin $Y$, Wang J, Lin X, Frayo SE, et al. Combining a CD20 chimeric antigen receptor and an inducible caspase 9 suicide switch to improve the efficacy and safety of T cell adoptive immunotherapy for lymphoma. PLoS One. 2013;8(12):e82742.

55. Maude SL, Teachey DT, Porter DL, Grupp SA. CD19-targeted chimeric antigen receptor T-cell therapy for acute lymphoblastic leukemia. Blood. 2015;125(26):4017-23.

56. Diaconu I, Ballard B, Zhang M, Chen Y, West J, Dotti G, et al. Inducible Caspase-9 selectively modulates the toxicities of CD19-specific chimeric antigen receptor-modified T cells. Mol Ther. 2017;25(3):580-92.

57. McMillan SJ, Crocker PR. CD33-related sialic-acid-binding immunoglobulinlike lectins in health and disease. Carbohydr Res. 2008;343(12):2050-6.

58. Pearce DJ, Taussig D, Zibara K, Smith LL, Ridler CM, Preudhomme C, et al. AML engraftment in the NOD/SCID assay reflects the outcome of AML: implications for our understanding of the heterogeneity of AML. Blood. 2006;107(3):1166-73.

59. Minagawa K, Jamil MO, Al-Obaidi M, Pereboeva L, Salzman D, Erba HP, et al. In vitro pre-clinical validation of suicide gene modified anti-CD33 redirected chimeric antigen receptor T-cells for acute myeloid leukemia. PLoS One. 2016;11(12):e0166891.

60. Barese CN, Felizardo TC, Sellers SE, Keyvanfar K, Di Stasi A, Metzger ME, et al. Regulated apoptosis of genetically modified hematopoietic stem and progenitor cells via an inducible caspase-9 suicide gene in rhesus macaques. Stem Cells. 2015:33(1):91-100.

61. Warfvinge R, Geironson L, Sommarin MNE, Lang S, Karlsson C, Roschupkina $T$, et al. Single-cell molecular analysis defines therapy response and immunophenotype of stem cell subpopulations in CML. Blood. 2017;129(17):2384-94.

62. Warda W, Larosa F, Neto Da Rocha M, Trad R, Deconinck E, Fajloun Z, et al. CML hematopoietic stem cells expressing ILIRAP can be targeted by chimeric antigen receptor-engineered T cells. Cancer Res. 2019;79(3):663-75.

63. Ballen KK, Koreth J, Chen YB, Dey BR, Spitzer TR. Selection of optimal alternative graft source: mismatched unrelated donor, umbilical cord blood, or haploidentical transplant. Blood. 2012;119(9):1972-80.

64. Amrolia PJ, Muccioli-Casadei G, Huls H, Adams S, Durett A, Gee A, et al. Adoptive immunotherapy with allodepleted donor T-cells improves immune reconstitution after haploidentical stem cell transplantation. Blood. 2006;108(6):1797-808.

65. Di Stasi A, Tey SK, Dotti G, Fujita Y, Kennedy-Nasser A, Martinez C, et al. Inducible apoptosis as a safety switch for adoptive cell therapy. N Engl J Med. 2011;365(18):1673-83.

66. Zhou X, Di Stasi A, Tey SK, Krance RA, Martinez C, Leung KS, et al. Longterm outcome after haploidentical stem cell transplant and infusion of $T$ cells expressing the inducible caspase 9 safety transgene. Blood. 2014;123(25):3895-905.

67. Zhou X, Dotti G, Krance RA, Martinez CA, Naik S, Kamble RT, et al. Inducible caspase-9 suicide gene controls adverse effects from alloreplete T cells after haploidentical stem cell transplantation. Blood. 2015;125(26):4103-13.

68. Paszkiewicz PJ, Frassle SP, Srivastava S, Sommermeyer D, Hudecek M, Drexler I, et al. Targeted antibody-mediated depletion of murine CD19 CAR T cells permanently reverses B cell aplasia. J Clin Invest. 2016;126(11):4262-72.
69. Griffioen M, van Egmond EH, Kester MG, Willemze R, Falkenburg JH, Heemskerk MH. Retroviral transfer of human CD20 as a suicide gene for adoptive T-cell therapy. Haematologica. 2009;94(9):1316-20.

70. Philip B, Kokalaki E, Mekkaoui L, Thomas S, Straathof K, Flutter B, et al. A highly compact epitope-based marker/suicide gene for easier and safer T-cell therapy. Blood. 2014;124(8):1277-87.

71. Koneru M, O'Cearbhaill R, Pendharkar S, Spriggs DR, Brentjens RJ. A phase I clinical trial of adoptive T cell therapy using IL-12 secreting MUC-16(ecto) directed chimeric antigen receptors for recurrent ovarian cancer. J Transl Med. 2015;13(102).

72. Jones BS, Lamb LS, Goldman F, Di Stasi A. Improving the safety of cell therapy products by suicide gene transfer. Front Pharmacol. 2014;5(254).

73. Kloss CC, Condomines M, Cartellieri M, Bachmann M, Sadelain M. Combinatorial antigen recognition with balanced signaling promotes selective tumor eradication by engineered T cells. Nat Biotechnol. 2013;31(1):71-5.

74. Lanitis E, Poussin M, Klattenhoff AW, Song D, Sandaltzopoulos R, June CH, et al. Chimeric antigen receptor $T$ cells with dissociated signaling domains exhibit focused antitumor activity with reduced potential for toxicity in vivo. Cancer Immunol Res. 2013;1(1):43-53.

75. Wilkie S, van Schalkwyk MC, Hobbs S, Davies DM, van der Stegen SJ, Pereira $A C$, et al. Dual targeting of ErbB2 and MUC1 in breast cancer using chimeric antigen receptors engineered to provide complementary signaling. J Clin Immunol. 2012;32(5):1059-70.

76. Grada Z, Hegde M, Byrd T, Shaffer DR, Ghazi A, Brawley VS, et al. TanCAR: A Novel Bispecific Chimeric Antigen Receptor for Cancer Immunotherapy. Mol Ther Nucleic Acids. 2013;2(e105).

77. Hegde M, Mukherjee M, Grada Z, Pignata A, Landi D, Navai SA, et al. Tandem CAR T cells targeting HER2 and IL13Ralpha2 mitigate tumor antigen escape. J Clin Invest. 2016;126(8):3036-52.

78. Li D, Hu Y, Jin Z, Zhai Y, Tan Y, Sun Y, et al. TanCAR T cells targeting CD19 and CD133 efficiently eliminate MLL leukemic cells. Leukemia. 2018;32(9):2012-6.

79. Qin H, Ramakrishna S, Nguyen S, Fountaine TJ, Ponduri A, StetlerStevenson M, et al. Preclinical Development of Bivalent Chimeric Antigen Receptors Targeting Both CD19 and CD22. Mol Ther Oncolytics. 2018;11(127-137)

80. Schneider D, Xiong Y, Wu D, Nlle V, Schmitz S, Haso W, et al. A tandem CD19/CD20 CAR lentiviral vector drives on-target and off-target antigen modulation in leukemia cell lines. J Immunother Cancer. 2017;5(42).

81. Morsut L, Roybal KT, Xiong X, Gordley RM, Coyle SM, Thomson M, et al. Engineering customized cell sensing and response behaviors using synthetic notch receptors. Cell. 2016;164(4):780-91.

82. Yuan $\mathrm{X}, \mathrm{Wu} \mathrm{H}, \mathrm{Xu} \mathrm{H}$, Xiong $\mathrm{H}$, Chu Q, Yu S, et al. Notch signaling: an emerging therapeutic target for cancer treatment. Cancer Lett. 2015:369(1):20-7.

83. Roybal KT, Rupp LJ, Morsut L, Walker WJ, McNally KA, Park JS, et al. Precision tumor recognition by $T$ cells with combinatorial antigen-sensing circuits. Cell. 2016;164(4):770-9.

84. Balakrishnan A, Goodpaster T, Randolph-Habecker J, Hoffstrom BG, Jalikis FG, Koch LK, et al. Analysis of ROR1 protein expression in human Cancer and Normal tissues. Clin Cancer Res. 2017;23(12):3061-71.

85. Srivastava S, Salter Al, Liggitt D, Yechan-Gunja S, Sarvothama M, Cooper K, et al. Logic-Gated ROR1 Chimeric Antigen Receptor Expression Rescues T Cell-Mediated Toxicity to Normal Tissues and Enables Selective Tumor Targeting. Cancer Cell. 2019;35(3):489-503.e488.

86. Roybal KT, Williams JZ, Morsut L, Rupp LJ, Kolinko I, Choe JH, et al. Engineering T Cells with Customized Therapeutic Response Programs Using Synthetic Notch Receptors. Cell. 2016;167(2):419-432.e416.

87. Sharma P, Wagner K, Wolchok JD, Allison JP. Novel cancer immunotherapy agents with survival benefit: recent successes and next steps. Nat Rev Cancer. 2011;11(11):805-12.

88. Fedorov VD, Themeli M, Sadelain M. PD-1- and CTLA-4-based inhibitory chimeric antigen receptors (iCARs) divert off-target immunotherapy responses. Sci Transl Med. 2013;5(215):215ra172.

89. Kim MS, Ma JS, Yun H, Cao Y, Kim JY, Chi V, et al. Redirection of genetically engineered CAR-T cells using bifunctional small molecules. J Am Chem Soc. 2015;137(8):2832-5.

90. Tamada K, Geng D, Sakoda Y, Bansal N, Srivastava R, Li Z, et al. Redirecting gene-modified $T$ cells toward various cancer types using tagged antibodies. Clin Cancer Res. 2012;18(23):6436-45. 
91. Ma JS, Kim JY, Kazane SA, Choi SH, Yun HY, Kim MS, et al. Versatile strategy for controlling the specificity and activity of engineered T cells. Proc Natl Acad Sci U S A. 2016;113(4):E450-8.

92. Kudo K, Imai C, Lorenzini P, Kamiya T, Kono K, Davidoff AM, et al. T lymphocytes expressing a CD16 signaling receptor exert antibodydependent cancer cell killing. Cancer Res. 2014;74(1):93-103.

93. Weiss A, Littman DR. Signal transduction by lymphocyte antigen receptors Cell. 1994;76(2):263-74.

94. Wu CY, Roybal KT, Puchner EM, Onuffer J, Lim WA. Remote control of therapeutic T cells through a small molecule-gated chimeric receptor. Science. 2015;350(6258):aab4077.

95. Juillerat A, Marechal A, Filhol JM, Valton J, Duclert A, Poirot L, et al. Design of chimeric antigen receptors with integrated controllable transient functions. Sci Rep. 2016;6(18950).

96. van Schalkwyk MC, Papa SE, Jeannon JP, Guerrero Urbano T, Spicer JF, Maher J. Design of a phase I clinical trial to evaluate intratumoral delivery of ErbB-targeted chimeric antigen receptor T-cells in locally advanced or recurrent head and neck cancer. Hum Gene Ther Clin Dev. 2013;24(3):134-42

97. Adusumilli PS, Cherkassky L, Villena-Vargas J, Colovos C, Servais E, Plotkin J, et al. Regional delivery of mesothelin-targeted CAR T cell therapy generates potent and long-lasting CD4-dependent tumor immunity. Sci Transl Med. 2014:6(261):261ra151.

98. Tchou J, Zhao Y, Levine BL, Zhang PJ, Davis MM, Melenhorst JJ, et al. Safety and efficacy of Intratumoral injections of chimeric antigen receptor (CAR) T cells in metastatic breast Cancer. Cancer Immunol Res. 2017;5(12):1152-61.

99. Correction: Mesothelin-Specific Chimeric Antigen Receptor mRNAEngineered T Cells Induce Antitumor Activity in Solid Malignancies. Cancer Immunol Res. 2015;3(2):217.

100. Song DG, Ye Q, Poussin M, Liu L, Figini M, Powell DJ Jr. A fully human chimeric antigen receptor with potent activity against cancer cells but reduced risk for off-tumor toxicity. Oncotarget. 2015;6(25):21533-46.

101. Liu X, Jiang S, Fang C, Yang S, Olalere D, Pequignot EC, et al. Affinity-tuned ErbB2 or EGFR chimeric antigen receptor T cells exhibit an increased therapeutic index against tumors in mice. Cancer Res. 2015;75(17):3596-607.

102. Caruso HG, Hurton LV, Najjar A, Rushworth D, Ang S, Olivares S, et al. Tuning sensitivity of CAR to EGFR density limits recognition of Normal tissue while maintaining potent antitumor activity. Cancer Res. 2015;75(17):3505-18

103. Arcangeli S, Rotiroti MC, Bardelli M, Simonelli L, Magnani CF, Biondi A, et al. Balance of anti-CD123 chimeric antigen receptor binding affinity and density for the targeting of acute myeloid leukemia. Mol Ther. 2017;25(8):1933-45.

104. Chen F, Teachey DT, Pequignot E, Frey N, Porter D, Maude SL, et al. Measuring IL-6 and sIL-6R in serum from patients treated with tocilizumab and/or siltuximab following CAR T cell therapy. J Immunol Methods. 2016:434(1-8)

105. Akpek G, Lee SM, Anders V, Vogelsang GB. A high-dose pulse steroid regimen for controlling active chronic graft-versus-host disease. Biol Blood Marrow Transplant. 2001;7(9):495-502

\section{Publisher's Note}

Springer Nature remains neutral with regard to jurisdictional claims in published maps and institutional affiliations.

Ready to submit your research? Choose BMC and benefit from:

- fast, convenient online submission

- thorough peer review by experienced researchers in your field

- rapid publication on acceptance

- support for research data, including large and complex data types

- gold Open Access which fosters wider collaboration and increased citations

- maximum visibility for your research: over $100 \mathrm{M}$ website views per year

At $\mathrm{BMC}$, research is always in progress.

Learn more biomedcentral.com/submissions 